\title{
Metinlerarası Bir Okuma: Karaağaçlar Altında Arzu
}

\author{
Reyhan Özer TANIYAN*
}

\section{Öz}

20. yüzyıla adını veren Modernizm, önceki yüzyıllar ile kıyaslandığında daha bireyci, yalnız ve yabancılaşmış bir toplumun yansımalarını içermekteydi. Bu modern toplum, çağa yön veren bilimsel ve pozitivist gelişmeleri inanışlarında ön plana çıkarıp toplumları bağlayan bütünleştirici değer ve inanışları rafa kaldırmıştır. Tüm bu değerlerin yokluğu insanın yaşamını mutsuz ve anlamsız kılmıştı. Dönemin edebiyatçıları da yapıtlarında çoğunlukla bu boşluğa düşen insanları ele almış ve modern insanın yalnızlığını resmetmiştir. Fakat, insanın yaşamı anlamsız bulmasını mitlerin eksikliğine bağlayan bazı düşünürler mitlerin doğru yorumlandıklarında modern toplumların etkin yaşam rehberleri olabileceğini öne sürmüşlerdir. Dolayısıyla da 20. Yüzyıldaki edebi eserlerde mitler sürekli kullanılan tematik bir kaynak ve düzen öğesi haline gelmiştir. Bu çalışmada eserlerinde mitlere gönderme yapan Amerikalı tiyatro yazarı Eugene O’Neill'in Karaağaçlar Altında Arzu'su ve konulaştırılan modern aile yapısı metinlerarasılık aracılığıyla incelenecektir. Makalenin çerçevesini, aile içi dengelerin ya da çarpıklıkların konu alındı̆̆ mitleşen eserler oluşturacaktır. Oyunun bel kemiğini oluşturan yasak aşk olgusu sırasıyla okuyuculara Sofokles'in Oedipus Rex, Seneca'nın Phaedra ve Euripides'in Hippolytus eserlerini ve son olarak da Euripides'in Medea adlı eserini hatırlatacaktır. Bu eserler, oyunda yeniden hayat bularak, modernist yazarların mitler ve söylencelerle toplumda ortak bir payda yaratmadaki nihai amacına hizmet edecektir. Bu bağlamda da metinlerarasılık, bu amaç ve yöntemlerin incelenmesinde gerekli olan kuramsal alt yapıyı sunacaktır.

Anahtar Kelimeler: Eugene O’Neill, Karaağaçlar Altında Arzu, söylenceler, metinlerarasılık, modernizm.

\footnotetext{
* Doktor Öğretim Üyesi, Pamukkale Üniversitesi, İngiliz Dili ve Edebiyatı Bölümü, Denizli, Türkiye. Elmek: rotaniyan@pau.edu.tr http://orcid.org/0000-0002-0285-1787.
} 


\title{
An Intertextual Reading of Desire Under the Elms
}

\begin{abstract}
Modernist literature contains the reflections of an individualistic and alienated society compared to the previous centuries. Ideologically, this society has brought the scientific developments and positivist thinking to the forefront, which caused the deterioration of the integrative values once bound societies. The absence of these values made life unhappy and meaningless. Modernism mostly dealt with man who fell into this void. In this context, there appeared an opinion that attributed the meaninglessness of life to the lack of myths. According to this idea, myths can be effective life guide for modern man. Therefore, myths were used as an organizing principle and a thematic resource. The article examines American playwright Eugene O'Neill's Desire Under the Elms with a focus on the modern family structure through intertextual relations. The framework of the article will be mythical stories with broken family bounds or distortions. The phenomenon of forbidden love that constitutes the backbone of the play will remind respectively of Sophocles' Oedipus Rex, Seneca's Phaedra and Euripides' Hippolytus, and Medea. These works serve the ultimate purpose of modernist writers in creating a common ground through myths and legends. In this context, intertextuality provides the necessary theoretical background to examine these goals and methods.
\end{abstract}

Keywords: Eugene O’Neill, Desire Under The Elms, mythic stories, intertextuality, modernism. 


\section{Extended Summary}

Modernist literature contains the reflections of a more individualistic, lonely, and alienated society compared to the previous centuries. In its belief system, this modern society has brought the scientific developments and positivist idea the forefront, which caused the deterioration of the integrative values and beliefs that used to bind societies together. The absence of all these binding values made human life unhappy and meaningless. Modernist literature mostly dealt with man who fell into this void and depicted the loneliness of the modern people. In this context, there appeared an opinion which attributed the meaninglessness of life to the lack of myths. According to this idea, myths, if interpreted correctly, can be effective life guide for the modern man. Therefore, myths were used both as an organizing principle and as a thematic resource in modernist literature. In this article, American playwright Eugene O'Neill's Desire Under the Elms will be examined with a particular focus on the depicted modern family structure through establishing intertextual relations. The framework of the article will be mythical stories with broken family bounds or distortions. The phenomenon of forbidden love, which constitutes the backbone of the play, will remind readers respectively of Sophocles' Oedipus Rex, Seneca's Phaedra and Euripides' Hippolytus, and finally Euripides' Medea. These works that revive in O'Neill's play serve the ultimate purpose of modernist writers in creating a common ground in society through myths and legends. In this context, intertextuality will provide the necessary theoretical background to examine all these goals and methods.

Myths have been in our life from the very beginning of the primitive times. It has shown its narrative power through stories full of successes or heroic deeds that nourish the dreams and desires of the human being. It has appeared in functional harmony with the narratives embellished with fantastic achievements. In this context, myths have undertaken an integrative role as being didactic and introducing role models or determining the cultural behaviours that bind social structures and institutions. For this reason, authors from all ages have been highly influenced by myths and the collective messages that are coded in then. Therefore, they have included myths or mythical references in their works.

The recognition of ancient myths by contemporary readers and their potential 
to acquire new meanings have made them an impressive and creative tool for all artists. Modern playwrights, for sure, could not remain indifferent to this influence and breathed new life to ancient myths and stories in their works. In fact, by looking at the much more harmonious and integrative picture of the past, modernist artists begun to reconsider the lost values of the dispersed and alienated modern society in which no common centre exists. As a representative figure of the American Drama, O'Neill uses the power of myths and mythological stories in his works. By establishing a connection between the Native American drama and cultural, and archetypal representations encoded in myths, he left his mark on literature. In his work, Desire Under the Elms, he makes use of motifs of the classical drama as well as myths and archaic stereotypes. Relatedly, in this article, O'Neill's revisiting of Sophocles' Oedipus Rex, Seneca's Phaedra and Euripides' Hippolytus and Medea is discussed in terms of intertextuality. In the play, there are intertextual themes such as forbidden love, desires, incest, and filicide as well as intertextuality in tragic characters, revolting figures, and victims. All these are well reflected through the characters and themes; thus, the related mythological figures and stories are revived in this modern text. As a result, in a modern setting, O'Neill produces a modern classical tragedy enriched with intertextual relations. 


\section{Giriş}

20. yüzyıl kayıtlara yeni bir dünyanın ve buna uygun olarak da gelişen yeni bir dünya görüşünün şekillenmeye başladığı dönem olarak geçmiştir. Döneme adını veren modernist akım, önceki yüzyıllarla kıyaslandığında daha bireyci, daha yalnız ve yabancılaşmış bir toplumun yansımalarını içermekteydi. Bu modern toplum, çağa yön veren bilimsel gelişmeleri inanışlarında ön plana çıkarıp, toplumları birbirine bağlayan bütünleştirici değer ve inanışları rafa kaldırmıştır. Bu ortak değerler yelpazesi dini inanışlardan tabulara, folklora, kültürel miraslara ve de aile bağlarına kadar toplumları birbirine bağlayan bütün anlamları içermekteydi. Tüm bu bağlayıcı değerlerin yokluğu insanın yaşamını mutsuz ve anlamsız kılmıştı. Dönemin edebi isimleri de yapıtlarında çoğunlukla bu boşluğa düşen insanları ele almış ve modern insanın yalnızlığını resmetmiştir. Fakat, insanın yaşamı anlamsız bulmasını mitlerin eksikliğine bağlayan Joseph Campbell gibi isimler mitlerin doğru yorumlandıklarında modern toplumların etkin yaşam rehberleri olabileceğini öne sürmüşlerdir. Bu manada, mitlerin sembolik ve psikolojik yönlerinin bilimle örtüştürerek modern insanın da benimseyeceği bir ortak payda olduğu düşünülmüştür (Segal 1978: 67). Dolayısıyla da 20. Yüzyılda üretilen edebi eserlerde mitler sürekli kullanılan bir yöntem haline gelmiştir. Bu çalışmada da eserlerinde yoğunlukla mitlere gönderme yapan Amerikalı tiyatro yazarı Eugene O'Neill'in Karaağaçlar Altında Arzu' adlı eseri ve konulaştırılan modern aile yapısı metinlerarasılık aracılığ 1 ile incelenecektir. Elbette, eser metinlerarasılık çerçevesinde irdelenebilecek pek çok farklı alımlamalara sahiptir. Fakat, bu çalışmada çerçeveyi, yüzyıllar boyunca onlara atfedilen aile içi dengelerin ya da çarpıklıkların konu alındığı mitleşen eserler oluşturacaktır. Dolayısıyla, olayın bel kemiğini oluşturan ana fikir, yani yasak aşk nesnesi, bizi Sofokles'in ölümsüz eseri Oedipus Rex'e götürecektir². $\mathrm{Bu}$ trajedinin satır aralarında ise Seneca'nın Phaedra ${ }^{3}$ ve Euripides' in Hippolytus ${ }^{4}$ adlı eserlerinin izleri görülmektedir. Bu eserlerdeki üvey anne - oğul ve baba arasındaki aşk, nefret ve intikam dürtülerinin O'Neill'in oyunundaki benzerlikleri ve de ele

1 Orijinal adı Desire Under The Elms olan oyun, Orhan Burian tarafından çevrilip 1945 tarihinde Maarif Bakanlığı Devlet Konservatuvarı Yayımları, no:22 serisi ile dilimize kazandırılmıştır. Fakat, çeviri dilinin güncelliği için makale içerisindeki metin alıntıları makalenin yazarı tarafindan çevrilmiştir.

2 http://classics.mit.edu/Sophocles/oedipus.html

3 www.theoi.com/Text/SenecaPhaedra.html

4 http://classics.mit.edu/Euripides/hippolytus.html 
alınan çarpık aşk üçgenin yarattığı trajedi yine Euripides'in $M e d e a^{5}$ 'sı ile güçlendirilmiştir. Tüm bu eserlerin, O'Neill'in oyununda yeniden hayat bulması, modernist yazarların mitleri ve söylenceleri kullanarak toplumda ortak bir payda yaratmadaki nihai amacına da hizmet etmektedir. Bu bağlamda da metinlerarasılık, tüm bu amaç ve yöntemlerin incelenmesinde gerekli olan kuramsal alt yapıyı sunacaktır.

Mitler en ilkel olarak kabul edilen zamanlardan günümüze kadar anlatılar ve hikayeler (mitos) olarak hayatımızın içinde hep yer almışlardır. Yeri gelmiş insanın hayallerini, arzularını besleyen başarılarla dolu hikayeleri ile anlatı gücünü göstermiş, yeri gelmiş insanüstü sınırlar ile bezenmiş anlatılarla da işlevsel uyumluluk içinde karşımıza çıkmıştır. Bu bağlamda, mitler didaktik, rol model ya da kültürel davranışları belirleyen, sosyal yapı ve kurumları birbirine bağlayan bütünleyici bir görevi üstlenmiştir. Bu nedenle, her çağdan farklı yazarlar mitlerden ve mitlerin içinde saklı olan kodlanmış kolektif mesajlardan oldukça etkilenmiş ve eserlerinde mitlere çokça yer vermişlerdir. Her ne kadar mitler içinde şekillendiği kültürün özelliklerine, diline ve yapısına has olarak kabul edilseler de her yeni ele alınışlarında alegorik ve metaforik anlamlarla yeniden yoğrulan farklı değerler kazanmış ve yaşamaya devam etmişlerdir. Yani mitler, "uzak geçmişteki bir gerçekliğin anlatı biçiminde yeniden yaşatılması" olarak hep var olmuşlardır (Malinowski 2000: 99). Bu nedenle özellikle edebi eserlerde tekrarlanan motiflerin, kutsal değerlerin ve kültürel döngülerin ortak bir paydası olarak sıkça okurların karşına çıkmaktadırlar. Antik mitlerin çağdaş okurlarca bu denli tanınmaları ve yeni anlamlar yüklenme olasılıkları tüm sanatçılar için etkileyici ve yaratıcı bir araca dönüşmüştür. Öyle ki modern tiyatro yazarları da bu etkilenmeye kayıtsız kalamamış ve eserlerinde antik mitler ve öykülere yeniden ruh kazandırmışlardır. Aslında, modern dönem sanatçıları geçmişin çok daha uyumlu ve bütünleyici tablosuna bakarak içinde bulundukları ortak bir merkezi olmayan, dağınık ve uzak modern toplumun yiten değerlerini yeniden ele almaya başlamışlardır. Bu durum en etkili şekilde dönemin önemli isimlerinden T.S. Eliot'1n yazdiğı makalede belirtilmiştir. Eliot'a (1996) göre, eser sahiplerinin geçmiş ve gelecek arasında köprü kurabilme yetisine sahip olmaları gerekmektedir: "Yalnızca şimdide değil, aynı zamanda geçmişin şimdisinde yaşamadıkça; yalnızca ölülerin değil, aynı zamanda yaşayanların da bilincinde olmadıkça [yazar] ne yapması gerektiğini bilemez"6 (98).

5 http://classics.mit.edu/Euripides/medea.html

6 "And he is not likely to know what is to be done unless he lives in what is not merely the present, but the present moment of the past, unless he is conscious, not of what is dead, but of what is already living" Eliot, Thomas Stearns. Tradition and the individual talent, The Sacred Wood. New York: Alfred A. Knopf, 1921; Bartleby.com, 1996. 
Buradan hareketle, Eliot' un tanımına uyan kimi yazarlar, modern dönem ve toplumdan edindikleri veya gözlemledikleri tutum ve yaklaşımları geçmişin belirgin olayları, diğer bir deyişiyle mitleşmiş olguları ile eşleştirmişlerdir. Aslında kurdukları bu bağ ile modern dünyanın anlamsız koşuşturmasını ve boşluğunu mitlerin olay ve karakter örgüleriyle anlamlandırmaya ve de belirli bir neden sonuç ilişkisi içerisine oturtmaya çalışmışlardır. Eliot'ın da işaret ettiği gibi “mitlerin kullanımında, çağdaşlık ile antik çă̆ arasında süregelen bir paralelliği manipüle ederken " (1975: 177), modern yazarlar birbirlerini etkileyerek daha sonraki nesillere aktarılacak yeni mesajlar ortaya çıkarmışlardır. Daha önceden de belirtildiği üzere, O’Neill, Amerikan tiyatrosunun öncül ismi olarak bu beceriyi eserlerine sıkça yansıtmıştır. Amerikan yerli tiyatrosu ile mitlere kodlanmış kültürel ve arketip temsiller arasında bir bağlantı kurarak edebiyata damgasını vuran zengin eserler bırakmıştır. Örneklendirmek gerekirse, Lazarus Laughed (1925) adlı oyunda O’Neill ölümünden dört gün sonra İsa'nın dirilttiği Beytanyalı Lazarus olayını işlemiştir. Mourning Becomes Electra (1931) adlı üçlemeye bakılırsa da Aeschylus'un Oresteia'sının yeniden anlatımı bulunur. Aeschylus'un Agamemnon, The Liberation Bearers ve The Eumenides oyunlar1, O'Neill'in versiyonunda Homecoming, The Hunted ve The Haunted olarak yer alır. Karakterler de öncül eserdekilerin yeniden isimlendirilmesidir. Oresteia'daki Agamemnon, Clytemnestra, Orestes ve Electra gibi önemli karakterlere sırasıyla General Ezra Mannon, Christine, Orin ve Lavinia olarak hayat verilmiştir. Yine bu üçleme içerisinde Oidipus ve Elektra Karmaşalarının ${ }^{8}$ varlığı modern dönemdeki psikolojik ve bağlantılı olarak Freudcu okumalara da örnek teşkil etmektedir.

Eserlerinde kurduğu bu köprü ile de bir nevi çağdaş Amerikan toplumunun kültürel davranışlarını ve inanışlarını mitleştirmiştir. Bu tarz etkileşimler ve yeniden mitleştirmeler, her ne kadar modern dönemde artarak devam etse de aslında sürekliliği olan bir kullanımdır. Bu süreklilik ve her yeni alımlamanın eserlerde ortak bakış açılar1 yaratması ise kaçınılmaz hale gelmiştir. Örneğin; O’Neill'in Amerikan edebiyatına miras olarak bıraktığı eserlere, antik dönem tiyatro eserlerinden arkaik dini öykülere kadar birçok farklı mitlerden alımlamalar işlenmiştir. Metin üzerinden örnekleri tartışmadan önce, O’Neill'in öyküsünü hatırlamak konunun irdelenmesinde yararlı olacaktır.

7 "In using the myth, in manipulating a continuous parallel between contemporaneity and antiquity [...]" T. S. Eliot, Ulysses, Order, And Myth, (Aksi belirtilmediği sürece metindeki tüm çeviriler makalenin yazarına aittir).

8 Detaylı bilgi için bknz. Sayfa 69: Jung, C. G. (1915). The theory of psychoanalysis. New York: Nervous and Mental Disease Publishing Co. 
Dul kalan Ephraim Cabot, New England çiftliğini, ondan nefret eden ama en az onun kadar açgözlü üç oğluna bırakıp onları terk eder. Eben, en genç ve akıllı kardeş, çiftliğin kendi annesinin hakkı olduğuna inanır, çünkü Eben’e göre Ephraim, Eben'in annesini durmaksızın ağır çiftlik işleri ile meşgul ederek kadının ölümüne sebep olmuştur. Bu yüzden de kendisinin de çiftlik üzerinde aynı hakka sahip olduğunu düşünmektedir. Diğer üvey iki kardeşinin çiftlikteki haklarını da babasından çalmış olduğu parayla satın alır. Ellerine para geçen Peter ve Simeon, hayallerini kurdukları kolay yoldan elde edilmiş zenginlik içerisindeki bir gelecek için Kaliforniya’ya giderler: "Altın tarlaları! Servet tam da toprağın üstünde öylece duruyor, alınmak için bekliyor!"9 (O’Neill 1988: 138). Sonradan, Ephraim, oldukça genç, güzel ve zeki yeni bir eşle geri döner. Bu yeni eş, Abbie, üvey oğlu olan Eben ile ilişki kurarak kocasını aldatır. Bu ilişki ardında bir meyve bırakır; Abbie, Eben'in çocuğuna hamiledir. Abbie, zeki olmasının yanı sıra oldukça da kurnazdır. Ephraim'e çocuğun babasının kendisi olduğuna inandırır. Böyle bir yalana ihtiyaç duyar, çünkü Abbie bilir ki o çocuk kendisinin çiftlikte hak iddia edebilmesi ve geleceğini garanti altına alabilmesi için çok önemlidir. Ephraim ise durumdan bihaber doğacak çocuğu için övünür. Lakin, ondan başka herkes bu durumdan şüphe duyar ve onunla açık bir şekilde aldatılmış koca olarak dalga geçerler. Çocuk doğar, fakat Eben'e delicesine âşık olan Abbie, çocuğun ilişkilerine bir engel olabileceğini düşünür. Öteki taraftan, Ephraim yeniden bir erkek evlada sahip olmanın verdiği mutluluğu yaşarken, Eben miras için yeni bir rakip geldiğini hesap etmekte, bütün komşuları da onları ve bu ihaneti konuşmaktadırlar. Bu durum ise Eben'i Abbie'den uzaklaştırmaktadır. Abbie bu duruma daha fazla katlanamaz ve çocuğu öldürür. Bu haber karşısında çılgına dönen Eben, Abbie'yi şikâyet eder. Bu şikâyet Eben'in Abbie için hissettiği derin ve büyük aşkı kendine itiraf etmeden önce gerçekleşir ve bu yüzden kendini de bu cinayete ortak olarak gösterir. Oyunun olay örgüsü basitçe bu şekildedir fakat bu olay örgüsünün altında O'Neill'in geçmişin, yani antik dönemin en önemli söylencelerine yapmış olduğu atıflar bulunmaktadır. Oyundaki çarpık aile ilişkileri, antik Yunan tragedyalarını anımsatır niteliktedir ve bu çağrışımlar da tam olarak metinlerarasılık kavramı çerçevesinde irdelenmelidir.

Aslında neredeyse ilk yazılı metinlerden beri süregelen metinlerarası ilişki, 1960'lardan bu yana metinlerarasılık adı ile kavramlaştırılmaya başlanmış olup, popüler bir edebiyat yaklaşımı olarak metin çözümlemelerinin de vazgeçilmez kavramı 
haline gelmiştir. Temelde genel olarak, "bütüncül bir yapıya kavuşturulması amacıyla bir edebî metnin dokusuna hem edebiyat alanından hem de başka alanlardan metin parçalarının katılması" (TDK) olarak tanımlanan metinlerarasılığın çıkış noktası da kullanımı gibi parçalıdır. Yani, kavram Julia Kristeva (1980) ile özdeşleştirilse de temel ilkeleri Northrop Frye'nin Eleştirinin Anatomisi (Anatomy of Criticism) (1957) adlı eserinde ayrıntılı bir şekilde verilmiştir. Frye, edebiyatı sözlü ilişkiler sisteminde, yaşam ve gerçeklik içeren bir varlık olarak görmüştür. Ayrıca bu savını, metinlerarasılık "ilişki ve farklılığa dayalı tipolojiyi [...] kapsıyor ${ }^{10 "}$ diyerek güçlendirmiştir (Clayton-Rothstein 1991:17). Ama, bu çalışmadaki ana amaç elbette kavramın kronolojik geçmişini irdelemek değildir, çünkü Terry Eagleton'un da belirttiği gibi kavramin kendisi uçsuz bir döngüdedir:

Anlam, belirli bir gösterene sıkı sıkıya iliştirilmiş, bir kavram değil, gösterenlerin potansiyel olarak sonsuz oyununun çıktısıdır. [...] Gösterenler sürekli olarak gösterilenlere, gösterilenler ise gösterenlere dönüşürler ve hiçbir zaman kendisi de bir gösteren olmayan nihai bir gösterilene ulaşamazsınız. (1990:139)

Kavramın farklı metinler arasındaki etkileşimi ve yazılı metinlerin ortaya çıkmasından beri var olduğunun kabulü, bu kavramı tanımlamaya çalışanlar tarafından zaten hep dile getirilmiştir: "Herhangi bir söyleyen, henüz gösterilemeyen nesneler karşısında bir Âdem değildir ki ilk kez adlandırsın” (Aktulum 1999: 28). Lakin, yine de metinlerarası terimi, Julia Kristeva deyince akla gelen ilk şeydir. Kristeva, Mikhail Bakhtin'nin metinlerini ilk ele aldığında bu terimi kullanmıştır, fakat, daha sonra, metinlerarasılığın tanımları üzerine birçok aydınlatıcı açıklamalarda bulunmuştur: "Her metin alıntıları mozaiği olarak yapılanır, her metin bir diğerinin içine geçmiş ya da dönüştürülmüş halidir"

Açıklamak gerekirse, her yeni metin kendi içerisinde daha önceden yazılmış başka bir metni potasında eritip kendisinin, yani, yeni metnin bir parçası haline getirmiştir; "Verilen bir metnin evreninde, diğer metinlerden alınan birkaç ifade birbiriyle kesişir ve birbirini etkisiz hale getirir"ll (Kristeva 1980: 36). Bu nedenle Kristeva, metinlerarasılığı, önceden yazılmış olan metinlerden alıntılar bulunduran bir mozaik olarak düşünmüştür. Önceki metinlerde söylenmiş olanlar ya da yazılmış olanlar, yeni metinlerde kendilerine bir kaynak, bir örneklenen metin, bir anıştırma, bir imitasyon, bir arketip ya da bir parodi olarak yer bulurlar.

10 "subsumes $[\ldots]$ the typology based on relation and difference."

11 "In the space of a given text, several utterances, taken from other texts, intersect and neutralize one another." 
Bütün edebi eserler, büyük bir ölçüde "yeniden yazma”dır (Eagleton 1983: 192), ve bu durum geçmiş dönemlere ait eserleri okuyanların farkında olmadan, yani bilinçdışı olarak, eserlerine bunları konu etme durumu da olabilmektedir. Bu bağlamda, Eagleton her eser bir yeniden yazma ürünüdür diye iddia etmektedir. Bu durumun ise tamamen bir aktarım olduğunu belirtir. Metinlerarasılıkta, aşina olunan fikirler, karakterler ya da olaylar ya genişletilmiş ya da etkisi altında kalınan olayları tamamen yeni bir durum içerisinde anlatmak olarak karşımıza çıkar ki bu durum yapı bozuculukta oldukça sık ele alınan bir olgudur. Yapı bozucular için, metinlerarasılık hem edebi metinler arasındaki ilişkiyi hem de onlarla diğer yazıya dökülmüş metinler arasında geçen bir diyalogu kastetmektedir. Belki de M. H. Abrams'ın metinlerarasılık tanımı, bu söylemler için en uygun çerçeveyi oluşturmaktadır. Ona göre, metinlerarasılık yaratıcı bir araçtır ve bu araç:

Herhangi bir yazınsal metnin başka metinlerde yankılandığı; ya da başka metinlerle bağlantısının açık veya örtülü alıntı ve göndermelerle kaçınılmaz olarak gösterildiği; ya da daha önce yazılan bir metnin kendisinden sonraki metinlere uyarlandığı, ya da ortak yazınsal kodlar ve geleneklere dahil edildiği çoklu yöntemlere işaret eder. (1981: 200)

Bu dönüşüm, alımlama, alıntılama ya da örneklendirme, edebi eserlerde bilinçli ya da bilinç dışı bir şekilde yapılmıştır. Her nasıl olursa olsun, "metinlerarası ilişki, eskimeye ve unutulmaya yüz tutan metinleri yeniden oluşturma ve onlara hayat verme gibi çok önemli bir görev de üstlenir" (Aktulum 2013: 202). İşte bu noktada okuyucular veya seyirciler, geçmişin değerli eserlerinin O'Neill'in oyununda yeniden sahnelenerek hayat bulmasını takip etmektedir. Olay örgüsünün altında yatan söylencelere ait çağrıŞımlar, oyundaki çarpık aile ilişkileri çerçevesinde antik Yunan tragedyalarına yeniden hayat vermektedir. Bu göndermeleri ele alacak olursak; ilk olarak Sofokles'in oyunu Oedipus Rex’ten başlamak gerekmektedir, çünkü bu eser, oyundaki aile içi yasak ilişki (ensest) ve Oidipus Karmaşası ${ }^{12}$ temalarının temellendirilmesindeki mihenk taşıdır.

Esinlenilen birinci eserde, Oidipus, bir kehanete göre babasını öldüreceği ve en sonunda da annesi ile evleneceği öngörülünce korku içindeki ailesi tarafından doğar doğmaz ülkesinden sürülür. Kaderine terk edilen Oidipus, Korinth Kral ve kraliçesinin himayesine alınır ve onların öz çocukları gibi bakılıp büyütülür. Yaşanan bazı tesadüfi olaylardan sonra gelecekte onu neyin beklediğini öğrenen Oidipus, çareyi Korinth’i terk 
etmekte bulur. Fakat istemsizce daha büyük bir lanetin eşiğine sürüklenir. Kaderinden kaçmaya çalışırken farkında olmadan kaderin ağına düşer ve kehanetin öngördüğü olaylar yaşanmaya başlar. Öz babasını öldüren Oidipus, annesini kendine eş yapar ve ondan çocukları olur. Trajik bir hal alan hayatları, gerçeklerin gün yüzüne çıkması ile dramatik sona ulaşır. Bu söylence, daha sonrasında, oğulun annesine karşı duyduğu aşkın ve bunun beraberinde de babanın bir rakip olarak görülmesinin yani düşmanlaştırılmasının psikanalisttik bir sentezi olan "çocuğun yasak sevgi nesnesi yani Oidipus Karmaşası" (Freud 1999: 166) adıyla literatüre geçmiştir.

Lakin, O’Neill eserinde bu durumu daha karmaşık bir şekilde ele almıştır, çünkü Eben adlı karakterin hayatında üç tane baskın anne figürü bulunmaktadır; bunlar annesi, Abbie ve hayat kadını Min'dir. Eserdeki anne figürleri ise Eben örneği ile işlenen Oidipus kompleksine yeni ve farklı yönler eklemiştir. Aslında, annelik problemi/ konusu eserin daha ilk sahnesinde sahne ve manzara tanımlarında doğrudan vurgulanmıştır:

Evin her iki yanında iki devasa karaağaç vardır. Aşağıya doğru uzanan dallarıyla çatının üzerine doğru eğilmişlerdir. Hem koruyup hem de emir altına alıyor gibi görünürler. Duruşlarında ezici, kıskanç bir şekilde kendine doğru çeken uğursuz bir analık vardır. Evdeki adamın yaşamıyla olan sıkı ilişskileri onları korkunç bir surette insanlaştırmıştır. Evin üstüne çökmüşlerdir. Sarkık memelerini, ellerini ve saçlarını çatıya yaslayıp dinlendiren bitkin kadınlar gibidirler ve her yağmur yağdığında göz yaşları damla damla akıp kiremitlerde çürürler. ${ }^{13}$ (O’Neill 1988: 136)

$\mathrm{Bu}$ iki karaağacın temsil ettiği Eben'in annesi ve anneliği koruyucu değil daha çok uğursuzdur. Tıpkı bir lanet gibi, evin üstüne yerleşmiş karaağaçlar gibi, Ephraim'in öldürdüğüne inandığı annesinin ruhu gibi hem eve hem de Eben'e musallat olmaktaydı. Eben'in yaşadığı duygusal çalkantılar ve eksikliklerin kaynağı olarak annesi oyunda karaağaçlar ile sembolleştirilmiştir. Oyunun sonlarına doğru da Eben'in Abbie'ye kustuğu nefrette de bir lanetleme ve bela figürü olarak hatırlanmıştır. İkinci anne figürü ise yeni üvey anne Abbie'dir. Çiftliğin peşinde olan Abbie, Eben'i görür görmez onu arzulamaya başlamış, gözünü ona dikmiştir. Öte yandan Eben de güzelliği karşısında büyülenmiştir. Bu hoşlanma, özellikle Eben ve Abbie’ nin, annesinin öldüğü odaya girdiği sahnede daha da artmış ve durumun anneye duyulan arzular

\footnotetext{
13 Two enormous elms are on each side of the house. They bend their trailing branches down over the roof. They appear to protect and at the same time subdue. There is a sinister maternity in their aspect, a crushing, jealous absorption. They have developed from their intimate contact with the life of man in the house an appalling humaneness. They brood oppressively over the house. They are like exhausted women resting their sagging breasts and hands and hair on its roof, and when it rains their tears trickle down monotonously and rot on the shingles.
} 
ile örneklendirilmesini mümkün kılmıştır. Aslında, o oda annesinin ölümünden beri kullanılmamaktadır. Fakat, eve sahip olmak isteyen Abbie, o odayı da ele geçirmesi gerektiğinin farkındadır. Bu sebeple, şehvete kapılan Eben, Abbie ile bu yasaklı odaya girerek hem anne eksikliğini hem de cinsel arzularını tatmin etmiştir. Böylece Oidipal arzular ve ensest teması da oyunda anılmıştır:

ABBIE: (Kollarını vahşi bir şehvetle dolar) [...] Senin için ölürüm! (Ona karşı duyduğu delice arzusuna rağmen, davranışlarında ve sesinde içten bir anne sevgisi vardır - şehvet ve anne sevgisinin korkunç bir dürüstlükle apaçık karışımı) Ananın yerini alacağım! Senin için o neyse ben de o olacağım! [...] Seni art niyetsiz öpeceğim, Eben -ananmış gibi aynı - ve sen de beni oğlummuşsun, benim oğlum gibi, iyi geceler der gibi öpebilirsin! Öp beni, Eben. (Çekinerek öpüşürler. Sonra aniden vahşi tutku onu [Abbie'yi] alt eder. Tekrar tekrar şehvetli bir şekilde öper ve [Eben] onu sarmalar ve öpücüklerine karşılık verir). ${ }^{14}$ (O’Neill 1988: 178)

Oyundaki bir diğer anne figürü ise hayat kadını Min karakteridir. Eben, bu kadının daha önceden üvey kardeşleri Simeon ve Peter ve hatta babası Ephraim ile bile ilişkisi olduğunu çok iyi bilmektedir. Fakat, bilerek ve isteyerek Min’e gitmektedir çünkü ona sahip olmanın aynı zamanda babasını da alt etmek olduğunu düşünmektedir: "EBEN: "Onun [Ephraim] ve sizin de [Peter ve Simeon] olmuş olabilir ama şimdi o [Min] benimki oldu!'5" (O’Neill 1988: 148).

Min, sahne üzerinde görülmemesine rağmen, Eben'in içsel ve cinsel çatışmalarının yansıtılması açısından önemlidir. Hatırlanacağı üzere, Eben'in istediğinde birlikte zaman geçirdiği kadın olan Min, elbette Abbie hayatlarına girene kadar, Eben'in hem annelik görevini üstlendiği hem de cinsel isteklerini giderdiği tek kişidir. Eben'in bu ruhsal karmaşası, annesinin aşkından dolayı babasına duyduğu, bilinçaltında gelişen düşmanlıktan doğmakta ve Abbie'nin gelişiyle daha da alevlenmektedir. Her iki adam da onun için acı çekmekte ve onu arzulamaktadır. Abbie, Eben'in yaşadığ1 içsel ve baba figürüne karşı göstermiş olduğu düşman tavırla da sergilendiği gibi dışsal çatışmayı etkilemektedir. Eben, Ephraim’i kendisi için bir düşman, bir rakip olarak görmekte ve onu saf dışı etmek istemektedir. Bu sebepten, Ephraim’i babalıktan reddetmiştir: "Demek istediğim - ben ondan değilim - onun gibi değilim - o ben

14 ABBIE--(both her arms around him--with wild passion) [...] I'll die fur ye! (In spite of her overwhelming desire for him, there is a sincere maternal love in her manner and voice--a horribly frank mixture of lust and mother love.) [...] I'll take yer Maw's place! I'll be everythin' she was t' ye! [...] I'll kiss ye pure, Eben--same 's if I was a Maw t' ye--an' ye kin kiss me back 's if yew was my son--my boy--sayin' good-night t' me! Kiss me, Eben. (They kiss in restrained fashion. Then suddenly wild passion overcomes her. She kisses him lustfully again and again and he flings his arms about her and returns her kisses) 15 "She may've been his'n - an' your'n, too but she is mine now!" 
değil! 16" (O’Neill 1988: 141). Eben'in bu kompleksi, yani annesine karş1 olan dayanılmaz zaafı ve annesinin onun üstündeki güçlü etkisi, onun nasıl bir karaktere sahip olacağını kısacası nasıl bir adam olacağını oyunun en başından beri şekillendirmiştir.

Oyununun diğer bir söylenceyle olan benzerliği, temelde yine bu düzlemden kaynaklanmaktadır. Bu yeni gönderme Phaedra'yı işaret etmektedir. Bu söylencede adı geçen Phaedra'nın, Theseus ve ilk karısından olan oğlu Hippolytus ile yaşadıkları bu oyunda kendini açıkça göstermektedir. Aslında, bu söylence sadece O’Neill'i değil birçok yazar, şair ve oyun yazarını da etkilemiştir. Phaedra söylencesi tarih boyunca çokça anlatılmış ve yeniden yorumlanmıştır. Bunlardan en önemlileri Yunanlı Euripides ve Romalı Seneca tarafindan anlatılanlardır. Her iki ismin eserleri arasında çok ince ayrımlar bulunmaktadır. Seneca'nın Phaedra isimli oyununda, Phaedra Theseus'un ikinci eşidir ve kısa bir zaman sonra da kocasının oğlu ile tanışır ve âşık olur. Fakat Hippolytus onun aşkını kabul edemez ve bu olay da Phaedra'yı Hippolytus’ten intikam almaya yönlendirir. Onu, kendisini tecavüz etmekle suçlar ve Theseus, bunu duyduktan sonra, oğlunu lanetler, sonrasında Hippolytus ölür. Söylencelerin doğası gereği Hippolytus’un ölümünün nedenleri birkaç farklı versiyonda anlatılmıştır fakat ortak olan tek nokta hepsinde ölümünün nedeninin Phaedra olduğudur. Euripides'in Hippolytus adlı oyununda ise, olay örgüsü, Hippolytus'un savaş tanrıçası Artemis'i onurlandırmak için aşk tanrıçası Afrodit'in onurunu reddetmesiyle daha bir karmaşık hale gelmiştir. İntikamını almak için, Afrodit, Hippolytus'un üvey annesi Phaedra'yı büyüler ve Hippolytus'un ölümüne neden olacak bir aşk ile ikisini birleştirir. Seneca'nın anlatımında, Phaedra daha kurnaz ve aldatıcı bir karakter olarak lanse edilirken, Euripides'in anlatımında Phaedra bir kurbandır. Bu sebepten Seneca'nın Phaedra'sının, eserdeki Abbie karakterine daha yakın olduğu söylemek çok zor olmayacaktır.

Söylencedeki karakterlerin ya da kahramanların tasvirlerine dayanarak denilebilir ki O’Neill, Cabot ailesini söylencedekilerle aynı şekilde kurgulayarak, mitlere oyununda hayat buldurmuştur. Hippolytus, Phaedra ve Theseus'un rolleri sırasıyla Eben, Abbie ve Ephraim ile yeniden can bulmuştur. Abbie, onu ilk başta reddeden Eben için hırslı ve şehvetli iken yasak aşklarının ve birlikteliklerinin sonlarını hazırlayacağından habersizdir. Olay örgüsünün başlangıcı da aslında söylenceye uygundur. Her iki üvey anne de üvey oğullarını tam da onlar babalarının varlıkları için birer tehdit durumlarındayken bulurlar. Her ikisi de gerçek duygularını nefretle 
saklamaya çalışırlar. Her iki gelişme de hızlı ve durdurulamaz bir biçimde yön bulur. Oyunun sonsözü de söylenceye benzemektedir: Ephraim yalnız bırakılır ve Eben'in laneti oğullarını da etkiler. Oyun ve söylence arasındaki farklılıklar oldukça nadirdir ve bu farklılıklar kendini sadece aşklarını paylaşmadaki istekliliklerinde ve de oğlunu lanetleyenin Ephraim değil de Eben'in olduğu sahnede kendini göstermektedir:

EBEN: (aldırış etmeden- işkence haline gelmiş tutkusuyla) Keşke ölseydin! ${ }^{17}$ Keşke bunlar olmadan önce seninle bir ben de ölseydim! (Öfkeyle) Ama intikamımı da alacağım! Anamın bana yardım etmesi için - geri gelip sana ve ona [Ephraim] musallat olması için dualar edeceğim

ABBIE--(kırılarak) Yapma, Eben! Yapma! ([Eben’in] önünde diz çöker, ağlar.) Sana kötü bir şey olsun istemedim! Affet beni, ne olur?

\section{[...]}

EBEN--(şiddetli bir kararlılıkla) Gidiyorum ben, söyleyeyim! Zengin olacağım orada, geri gelip çaldığı çiftlik için onunla hesaplaşacağım - İkinizi de sokağa atacağım - yollarda dilenip sokaklarda yatacaksınız - sen ve senin oğlun, ikiniz de açlıktan sefillikten gebereceksiniz! (En sonunda histeriktir.)

ABBIE--(titreyerek- çekinerek) O senin de oğlun, Eben.

EBEN--(azap içinde) Keşke hiç doğmasaydı! Keşke şimdi, şu an ölse! Keşke onu hiç görmeseydim! Onun yüzünden - o yüzden doğurdun, çalmaya bahanen olsun diye - bu her şeyi değiştirdi! (O’Neill 1988: 193-94)

Eben'in hırs, üzüntü ve kin dolu bu konuşmaları oyunun gidişatında etkili olan başka bir söylenceye olan referansı da beraberinde getirmektedir. Eben'in şiddetle yoğrulmuş sözleri onların laneti haline dönüşür ve Abbie kendini, aşkını ve de bağlılığını kanıtlamak için Eben'in arzuları gibi görünen kehanetlerini yerine getirir; oğullarını öldürür. Abbie ve Eben'in bu trajik kaderi ve de hikayesi okuyucuyu bir diğer söylenceye, Medea’nın hikâyesine götürmektedir. Bu söylence de Euripides

17 EBEN--(unheedingly--with tortured passion) I wish ye was dead! I wish I was dead along with ye afore this come! (ragingly) But I'll git my vengeance too! I'll pray Maw t' come back t' help me--t' put her cuss on yew an' him!

ABBIE--(brokenly) Don't ye, Eben! Don't ye! (She throws herself on her knees before him, weeping.) I didn't mean t' do bad t' ye! Fergive me, won't ye?

$[\ldots]$

EBEN--(with fierce determination) I'm a-goin', I tell ye! I'll git rich thar an' come back an' fight him fur the farm he stole--an' I'll kick ye both out in the road--t' beg an' sleep in the woods--an' yer son along with ye--t' starve an' die! (He is hysterical at the end.)

ABBIE--(with a shudder--humbly) He's yewr son, too, Eben.

EBEN--(torturedly) I wish he never was born! I wish he'd die this minit! I wish I'd never sot eyes on him! It's him--yew havin' him--a-purpose t' steal--that's changed everythin'! 
tarafından kaleme alınmıştır. Bu söylence ise bahsi edilen diğer söylencelerin üstüne kurgulanmıştır. Bilindiği üzere, Medea kendisini başka bir kadın için terk eden kocası Jason'dan intikam alabilmek için çocuklarını öldürmüş ve vahşi bir anne olarak literatürde yerini almıştır. Çocuklarını öldürüp öldürmemek gibi bir seçim hakk1 da olmasına rağmen, Medea düşünmeden onları katletmiştir. Yunan mitolojisinde en büyük günahlardan biri olarak değerlendirilen evlat katilliği, Medea'nın adı ve hikayesi ile sembolleştirilmiştir. Ve de bu söylenceyi alımlayan eserlerde de kendi kanından ve canından olan birini hunharca katleden kadın, katil bir anne prototipi olarak işlenmiştir. Önceden irdelenen olaylarla da bağlantılı olarak, Abbie yasak aşkı Eben'den bir çocuk sahibi olmuştur. Tıpkı Medea gibi, Eben'e olan aşkını ispat etmek için, Abbie de kasıtlı olarak, yani bilerek ve isteyerek, kendi çocuğunun hayatına son vermiştir. Dahası, bu çocuk çiftlikte kendisinin geleceğini garantileyecek ve ailenin devamını sağlayacak bir erkek evlat olduğu için herkes için önemlidir. Jason'un Medea'yı lanetlediği gibi Eben de Abbie'yi lanetler, fakat yaptığından pişman olan Eben suçluluk duygusu ile affını ister. Ancak, oyunun sonunda yaşanılanlardan sonra, tıpkı Thesus'un Hippolytus'u lanetlediği gibi, Ephraim de her ikisini trajik bir sona mahkûm eder ve mitin işlenişini tamamlanmış olur.

CABOT: (onlara bakar, yüzü beton gibi. Uzun bir duraklama- kindar bir şekilde) Tam da bir çift katil kumru oldunuz! Aynı yağlı urgana beraber asılmalı rüzgârda sallanarak oracıkta çürümelisiniz- benim gibi aptal yaşlılara yalnızlıklarına katlanmaları, sizin gibi genç aptallara şehvetlerine yenik düşmemeleri için ibret olsun diye! ${ }^{18}$ (O’Neill 1988: 204)

Sonuç: Ephraim'in bu ahı ile oyun sona erer. Hepsi kaderlerin uygun gördüğü dramatik bir sonla yaptıklarının cezasını çekerler. Çağrıştırdıkları söylenceler gibi oyunun perdeleri de kapanır. Alkışlar O’Neill'in ustalığınadır. Gündelik hayatta yaşanabilecek olayları ve sıkıntıları dramatize edebilmedeki mükemmel ustalığını, eski ve yeni birlikteliğini klasik mitler ile sabırla oyunlarına işlerken göstermektedir. Oyunlarını kaleme alış yöntemi Amerikan sahnesinde mevcut olan bir geleneğin ürünü değildir. O’Neill, mitleri kullanırken klasik formun içinde yerel ve gündelik içeriği eritmiştir. Bunu yaparken de mitlerdeki sınıf farklılıklarını, karakter soyluluğunu ve de demokrasi anlayışını evrenselliğe uygun olarak modern zamanlara uyarlamıştır. Dolayısıyla da O'Neill'in gerçekçi ve bir o kadar da hayalperest kalemi ile bu uyar-

18 CABOT--(stares at them, his face hard. A long pause--vindictively) Ye make a slick pair o' murderin' turtle doves! Ye'd ought t' be both hung on the same limb an' left thar t' swing in the breeze an' rot--a warnin' t' old fools like me t' b'ar their lonesomeness alone--an' fur young fools like ye t' hobble their lust. 
lamalar Amerikan toplumunun modern zamanlardaki panoramasını resmetmektedir. Makalenin başında da belirtildiği gibi mitlerin bağlayıcı ve bütünleştirici özelliğine vurgu yapan kuramcılar ve çalışmaları ile modern dönem yazarları eserlerinde mitlere yer vermişlerdir. O’Neill de eserlerinde tam da bunu gerçekleştirmiştir. Karaağaçlar Altında Arzu adlı eserinde mitleri metinlerarasılık yöntemi ile işlemiştir. Olayın örgüsünü yasak aşk hikayesi üzerine kurgulayan O’Neill, okuyucuyu Sofokles'in ölümsüz eseri Oedipus Rex'e götürerek benzer olayları tecrübe eden Phaedra, Hippolytus ve Medea ile tanıştırmıştır.

Klasik tragedyalardaki olaylara kendi içinde yeniden hayat vermiş bu eser, olaylar ve karakterler arasında benzerlikler yaratmış ve bunun sonucu olarak da modern dönemde yazılmış olan bir eserle antik dönemde yazılan eserler arasında köprü kurarak metinlerarası özellikleri kendi içerisinde barındırmıştır. Eserde, metinlerarasılığa örnek teşkil edebilecek konular; antik dönem eserlerinden bölümler, günaha giren ve pişmanlık yaşayan çiftler, trajik ve güçlü aşklar, yasaklanan arzular, baba figürüne karşı isyan, karmaşık aşk ve nefret ilişkileri, çocuk kurbanlar, geçmişin insanın yakasını bırakmayışı ve karakterlerin iç çatışmaları olarak sıralanmaktadır. Tüm bu özellikler, eserde modern dönemin çerçevesinde ele alınmış, yani başka bir deyişle, antik dönem olayları ve karakterleri modern dönemle birleştirilerek yeniden yazılmıştır. Bu şekilde de tıpkı çalışmanın en başında da tartışıldığı gibi, O’Neill geçmiş ve günümüz ile bağ kurmuş, metinlerarası ilişki çerçevesinde eskimeye yüz tutan metinleri yeniden oluşturarak onlara hayat vermiştir. Sonuç olarak da modern bir kurgu ve olay örgüsünde, klasik ve antik döneme ait göndermelerle modern-klasik bir tragedya elde edilmiştir. 


\section{Kaynakça}

Abrams, M. H. A. (1981). Glossary of literary terms. New York: Holt, Rinehart and Winston.

Aktulum, K (1999). Metinlerarası ilişkiler. Ankara: Öteki Yayınevi.

Aktulum, K. (2013). Folklor ve metinlerarasılık. Konya: Çizgi Kitabevi.

Clayton, J. and Rothstein, E. (1991). Figures in the corpus: Theories of influence and intertextuality. In J. Rothstein (Eds.) Influence and Intertextuality in Literary History (pp. 3-35). Madison, Wisconsin: The University of Wisconsin Press.

Eagleton, T. (1983). Literary theory: Introduction. Oxford: Basil Blackwell.

Eagleton, T. (1990). Edebiyat kuramı. (Çev. Tuncay Birkan). Sanat ve Kuram Dizisi: 11. İstanbul: Ayrıntı Yayınları.

Eliot,T.S. (1975). Ulysses, order and myth. In Selected prose of T.S. Eliot. (pp. 175-8). London: Faber and Faber.

Eliot, T.S. (2013). T.S. Eliot- gelenek ve bireysel yetenek. (Çev. Oğuz Tecimen). Notos 40 (pp. 94-98).

Euripides. Hippolytus. http://classics.mit.edu/Euripides/hippolytus.html

Medea. http://classics.mit.edu/Euripides/medea.html

Freud, S. (1961). The dissolution of the oedipus complex. In The ego and the id and other works, Vol. XIX. (pp. 171 - 179). London: The Hogarth Press.

Freud, S. (1999). Psikopatoloji. (Çev. Hakan Atalay). Payel Freud Kitaplı̆̆ı, İstanbul, Payel Yayınevi.

Jung, C. G. (1915). The theory of psychoanalysis. New York: Nervous and Mental Disease Publishing Co.

Kristeva, J. (1980). The bounded text. In L. S. Roudiez (Ed.), Desire in language: A semiotic approach to literature and art (pp. 36-63). New York: Columbia University Press.

. (1986) Word, dialog and novel, In Toril Moi (Ed.), The kristeva reader (pp. 34-61). New York: Columbia University Press.

Malinowski, B. (2000). Büyü, bilim ve din. (Çev: S. Özkal), İstanbul: Kabalcı Yayınevi.

O’Neill, Eugene. (1988). Desire Under the Elms. O’Neill Complete Plays. 1920-1931. (pp. 317-78) New York: Penguin.

Robert A. Segal. (1978). Joseph campbell's theory of myth: An essay review of his oeuvre. Journal of the American Academy of Religion, Volume XLVI(1), 67. https://doi. org/10.1093/jaarel/XLVI.1.67

Seneca. (1917). Tragedies. (Trans. Miller, Frank Justus). Loeb Classical Library Volumes. London: William Heinemann Ltd. www.theoi.com/Text/SenecaPhaedra.html.

Sophocles. Oedipus the Rex. http://classics.mit.edu/Sophocles/oedipus.html

Türk Dil Kurumu Sözlükleri. (12 Şubat 2021). Metinlerarasılık https://sozluk.gov.tr/ 